\title{
More than technology alone
}

\section{DOI: 10.1039/b607997k}

Traditionally, developments in the labon-a-chip community have been technology-pushed, mainly guided by analytical chemists, micro-machinists and material scientists, rather than demand-pulled. Applications such as LabChip ${ }^{\mathbb{R}}$ from Caliper (Fig. 1) and i-STAT from Abbott Point of Care (Fig. 2) can now be found on the market, solving practical problems for users. However, the field is still lacking the promised breakthroughs and this trend will continue as long as we keep using a purely technologicallydriven approach. We therefore claim that for the long-term survival of this field a demand-pulled and market-driven approach is of the utmost importance. This article is framed around the medical applications of lab-on-a-chip technologies in the Netherlands; however, the results go beyond the Dutch context and are relevant to other countries experiencing similar technological changes.

Lab-on-a-chip scientists working on medical applications must consider diverse aspects such as user-friendliness, industrial collaboration, social acceptance, health care insurance, and various stakeholder interests in evaluating their research. All these interrelated issues make this already multifaceted area of technological innovation even more complex, but how should we deal with this? Part of the answer might lie in the hands of social scientists working in Innovation Studies. Since the 1970s an approach known as Technology Assessment (TA) has been developed in an attempt to deal with such complexities. In its origins, TA was merely an inward-looking discipline aiming to predict the course of

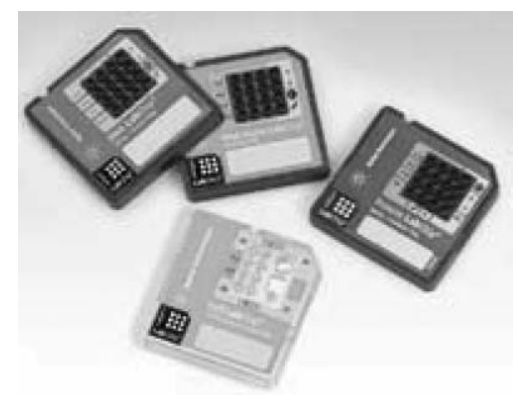

Fig. 1 LabChip ${ }^{\circledR}$ from Caliper. technological advances and functioning as a warning mechanism, thus striving to forecast potential harmful effects. Due to the unpredictable nature of innovations, this linear approach (as in the famous Chicago World Fair's (1933) slogan: "science finds, industry applies, man conforms") turned out not to be very useful or reliable. Instead, an evolutionary model was proven to be more suitable. This view is characterized by feedback and feed-forward linkages among all relevant stakeholders involved in the different stages of development and use of new technologies. In brief, innovation is not a relay race in which the baton is passed from the scientist, via industry, to the end-user. It is much more like a jigsaw puzzle, where the pieces change while trying to fit them together. Thus, TA became a process that not only includes scientists and traditional stakeholders in technology development, but also gives a voice to previously underexposed stakeholders that bring other relevant questions into the discussion. Complexity increases when we realize that the various stakeholders are subject to change in their own environments, such as public regulation leading to health care competition. Also, cultural differences in technology and markets between geographical regions are important issues to consider when applying the technology globally. In other words, it is more than technology alone that makes or breaks innovative applications.

Another important issue to consider is the so-called 'Collingridge dilemma' which states that technologies become

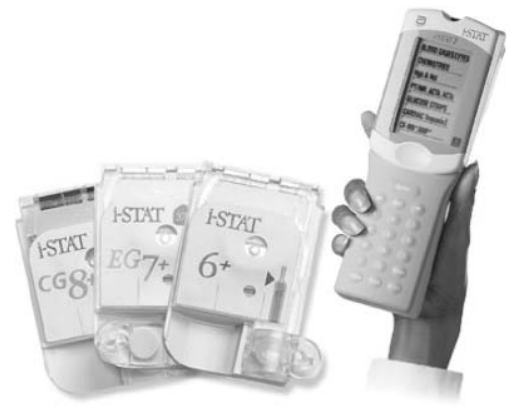

Fig. 2 i-STAT from Abbott Point of Care. more difficult to influence over time owing to investments and structures already in place, while at its early stages opportunities to steer are richest, but hard to find. ${ }^{1}$ Adapted approaches of TA, such as Constructive TA, attempt to actively enrich technological developments while they are still on the drawing board; $\uparrow$ involving all relevant stakeholders' wishes and needs. ${ }^{4,5}$ Thanks to this wide variety of standpoints, Constructive TA allows for a more constructive assessment of opportunities for promising technological applications and it creates room to anticipate futures under different scenarios.

Over the past year, a Constructive TA project has been conducted for medical applications of lab-on-a-chip technology in the Netherlands. A wide diversity of stakeholders were invited to debate the future of the technology and identify promising applications. The discussions included economic, political and sociocultural aspects, and potentially successful medical applications were also debated. Before we continue to discuss the possible added value of Constructive TA we will give three examples that illustrate cases where the technology failed to develop as foreseen:

(1) In the early 1990s, authors such as Manz et al., Harrison et al., and Verpoorte et al., ${ }^{2,3,6}$ had already touched upon the promise of $\mu$ TAS devices for use outside the laboratory. For medical devices this was soon linked up with the ability to measure (bio)chemical substances when and wherever needed, a process known as Point-of-Care testing. However, very few of these applications are on the market or in use today. This gives rise to the question: What are the chances of developing and facilitating the application of these technologies such that they can have an improving impact on our everyday lives?

(2) General practitioners often see patients with symptoms ranging from fever to the early stages of a heart attack.

$\uparrow$ Although we address early-stage technologies, the approach assumes that at least a scientific community must be in place. 
Technically it is possible to equip general practitioners with small instruments to measure the level of specific proteins in the patient's blood and exclude the possibility of a heart attack in the diagnosis. Although these instruments are already available on the market, and everyone seems to recognize the social and economic advantages of this application, they are still not used by Dutch general practitioners. Why is this?

(3) Frequent monitoring of the drug levels in a patient's blood will often contribute significantly to the effectiveness of treatments. Lab-on-a-chip technology offers possibilities to address these needs with devices that can be used either by general practitioners or by patients themselves. However, these needs are not being seriously addressed by the health care industry. Why is this?

These anecdotes show that scientists should not wait until they are approached by the business community looking for useful inventions to commercialize. What is needed are meetings between scientists, the medical community, industry, investors, health care insurers, patient organisations and government. This would reveal the relevance of inventions in the early stages of development, in other words: where possibilities to steer are still viable. The Dutch Constructive TA project on lab-on-a-chip technology represents a step forward in the assessment of valuable medical applications. It illustrates how discussions in a trans-disciplinary group, which includes all relevant stakeholders, are highly valued by the participants. Most participants indicated that the methodology helped them to articulate a broader range of aspects in their interpretation of the future of these applications. However, this is just the initial step, and further efforts are necessary to continue in this positive direction.

What is the message for the lab-on-achip community? Multi-stakeholder initiatives, highlighting the relevance of a wide variety of viewpoints in assessing potential applications, are needed. This implies initiatives that include 'unconventional' stakeholders such as health care insurers, business investors, or general practitioners. Furthermore, there is a strong need for conducting experiments that build on trans-disciplinary collaboration in the field of use. The authors do not claim that every lab-on-a-chip researcher should be involved in such activities since basic research will always be necessary. Nevertheless, for the duration of this field of endeavour, it is important that part of the research also focuses on closing the gap between science and practice; after all "more than technology alone" is required for success in practical application.

Rutger O. van Merkerk

Department of Innovation Studies, Utrecht University, The Netherlands r.vanmerkerk@geo.uu.nl

\section{Albert van den Berg}

MESA+ Research Institute, University of Twente, The Netherlands a.vandenberg@ewi.utwente.nl

\section{References}

1 D. Collingridge, The social control of technology, London, Pinter Publishers, 1980.

2 D. J. Harrison, A. Manz, Z. Fan, H. Lüdi and M. Widmer, Capillary electrophoresis and sample injection systems integrated on a planar glass chip, Anal. Chem., 1992, 64, 1926-1932.

3 A. Manz, N. Grabber and H. M. Widmer, Miniaturized total chemical analysis systems: a novel concept for chemical sensing, Sens. Actuators, B, 1990, 244-248.

4 Managing Technology in Society. The Approach of Constructive Technology Assessment, ed. A. Rip, Th. Misa and J. W. Schot, London, Pinter Publishers, 1995.

5 J. W. Schot and A. Rip, The Past and Future of Constructive Technology Assessment, Technol. Forecast. Soc. Change, 1997, 54, 251-268.

6 E. Verpoorte, A. Manz, H. Lüdi, A. E. Bruno, F. Maystre, B. Krattiger and H. M. Widmer, A silicon flow cell for optical detection in miniaturized total chemical analysis systems, Sens. Actuators, $B, 1992,6,66-70$. 